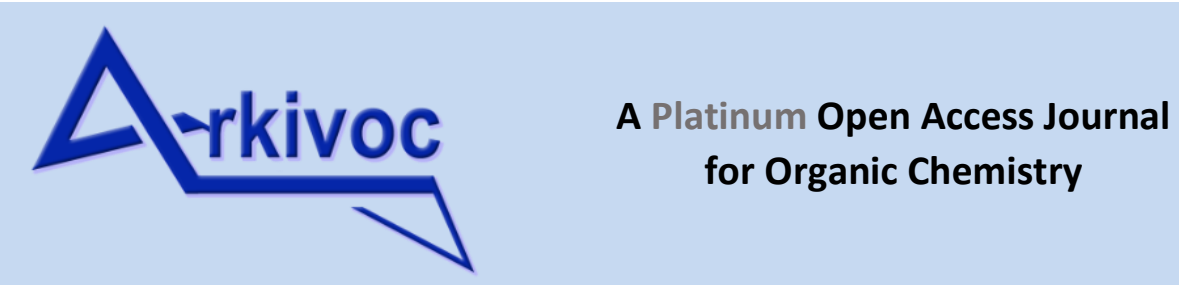

DOAJ Seal

Arkivoc 2021, part viii, 265-276

\title{
High yield synthesis of trans-azoxybenzene versus 2-isopropoxy-4-nitrobenzoic acid: influence of temperature and base concentration
}

\author{
J. Jonathan Nué-Martínez, Ibon Alkorta, and Christophe Dardonville* \\ aInstituto de Química Médica, IQM-CSIC, C/ Juan de la Cierva 3, 28006, Madrid, Spain \\ Email: dardonville@iam.csic.es
}

This article is dedicated to Prof. José Elguero on the occasion of his $86^{\text {th }}$ birthday

Received 02-09-2021

Accepted 05-23-2021

Published on line 06-13-2021

\section{Abstract}

The reported two-step synthesis of 2-isopropoxy-4-nitrobenzoic acid from 2-hydroxy-4-nitrobenzoic acid, using iodopropane $/ \mathrm{K}_{2} \mathrm{CO}_{3}$ and subsequent hydrolysis of the isopropyl 2-isopropoxy-4-nitrobenzoate intermediate with $45 \% \mathrm{NaOH} / \mathrm{THF}-\mathrm{EtOH}$ at $80{ }^{\circ} \mathrm{C}$, was reconsidered. (Z)-1,2-bis(4-carboxy-3isopropoxyphenyl)diazene-1-oxide derivative (3), which was isolated as main product (92\%) of the reaction, was characterized by $I R,{ }^{1} \mathrm{H},{ }^{13} \mathrm{C}$, and ${ }^{15} \mathrm{~N} N M R$ spectroscopy. The ${ }^{15} \mathrm{~N}$ chemical shifts were consistent with the trans-configuration for this azoxybenzene derivative. As an alternative, synthesis of 2-isopropoxy-4nitrobenzoic acid was accomplished in high yield (82\%) working at room temperature and using lithium hydroxide instead of concentrate $\mathrm{NaOH}$. Incorrect reaction temperature report or measurement in the published protocol (J. Org. Chem. 2011, 76, 7040) probably accounts for the discrepancies with our findings.

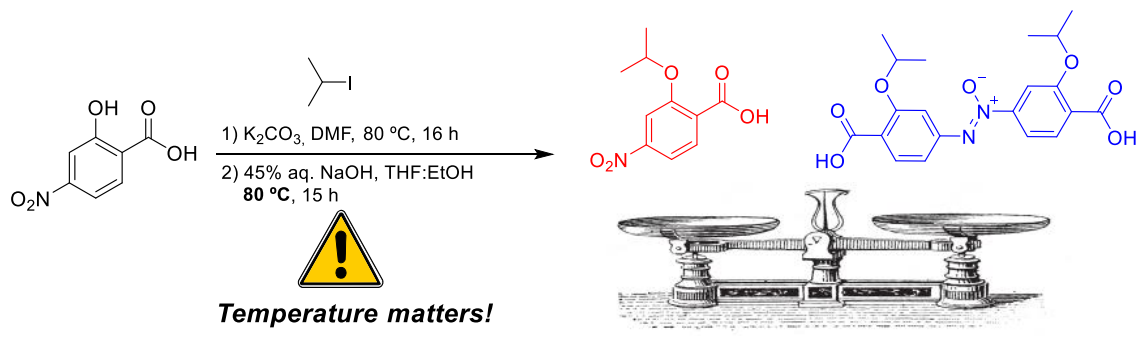

Keywords: Azoxybenzene; ${ }^{15}$ N NMR spectroscopy; infrared spectroscopy; 2-isopropoxy-4-nitrobenzoic acid; GIAO 


\section{Introduction}

During our project dedicated to the design of new dicationic compounds active against kinetoplastid parasites, ${ }^{1-4}$ we needed to prepare 2-isopropoxy-4-nitrobenzoic acid (1). The two-steps synthesis of this compound had been reported earlier by Adler \& Hamilton. ${ }^{5}$ Their synthetic approach consisted in the reaction of 2-hydroxy-4-nitrobenzoic acid with an excess of 2-iodopropane to form the di-alkylated intermediate 2 . After an aqueous workup, the crude compound was treated with $45 \%$ aqueous $\mathrm{NaOH}$ in THF/EtOH at $80^{\circ} \mathrm{C}$ to yield pure 1 ( $72 \%$ overall) by acid workup according to the reported procedure (Scheme 1). ${ }^{5,6}$

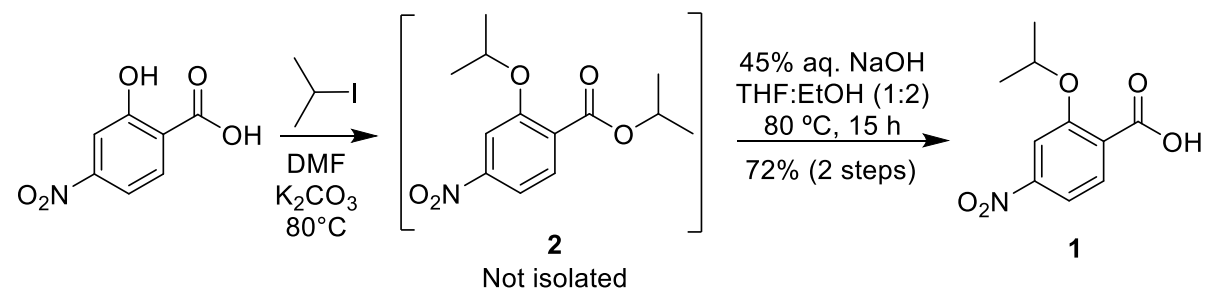

Scheme 1. Reported two-step synthetic route to 2-isopropoxy-4-nitrobenzoic acid (1). ${ }^{5}$

We tried to synthesize 1 following this reported procedure and, to our surprise, compound $\mathbf{1}$ was not obtained whereas a new compound (3), structurally closely related to 1 , was consistently obtained as major product (72-89\%) of the synthesis (Scheme 2). This was surprising because the occurrence of this major product was not mentioned by the authors (who reported $72 \%$ yield of $\mathbf{1}$ for this reaction, without any chromatographic purification). ${ }^{5}$

In the present paper, we report the isolation and full spectroscopic characterization by $I R,{ }^{1} \mathrm{H},{ }^{13} \mathrm{C}$, and ${ }^{15} \mathrm{~N}$ NMR of (Z)-1,2-bis(4-carboxy-3-isopropoxyphenyl)diazene-1-oxide (3), which is the major product of this synthesis using the reported protocol. ${ }^{5}$ We investigated the cause for the different outcome of this reaction with respect to the literature report. Finally, we describe a practical two-step procedure for the synthesis of 1 with $82 \%$ overall yield.

\section{Results and Discussion}

\section{Synthesis of compound 1}

In all our attempts (from $180 \mathrm{mg}$ to $5 \mathrm{~g}$ scale) to prepare 2-isopropoxy-4-nitrobenzoic acid (1) following the reported $d^{5}$ two-step protocol shown in Scheme 1, 1 was not detected in the crude reaction mixture whereas azoxybenzene $\mathbf{3}$ was isolated by crystallization from EtOAc and fully characterized (see below).

Since azoxybenzene $\mathbf{3}$ was formed in the second step of the reaction, different conditions of hydrolysis of benzoate 2 (i.e. base, concentration, temperature) were tested (Table 1). When the reaction was performed with $45 \%$ aq. $\mathrm{NaOH}$ at $60{ }^{\circ} \mathrm{C}$ and $40{ }^{\circ} \mathrm{C}$ (entries 1-2), the expected acid 1 was obtained as major product (70 and $81 \%$ detected by HPLC-MS, respectively). 


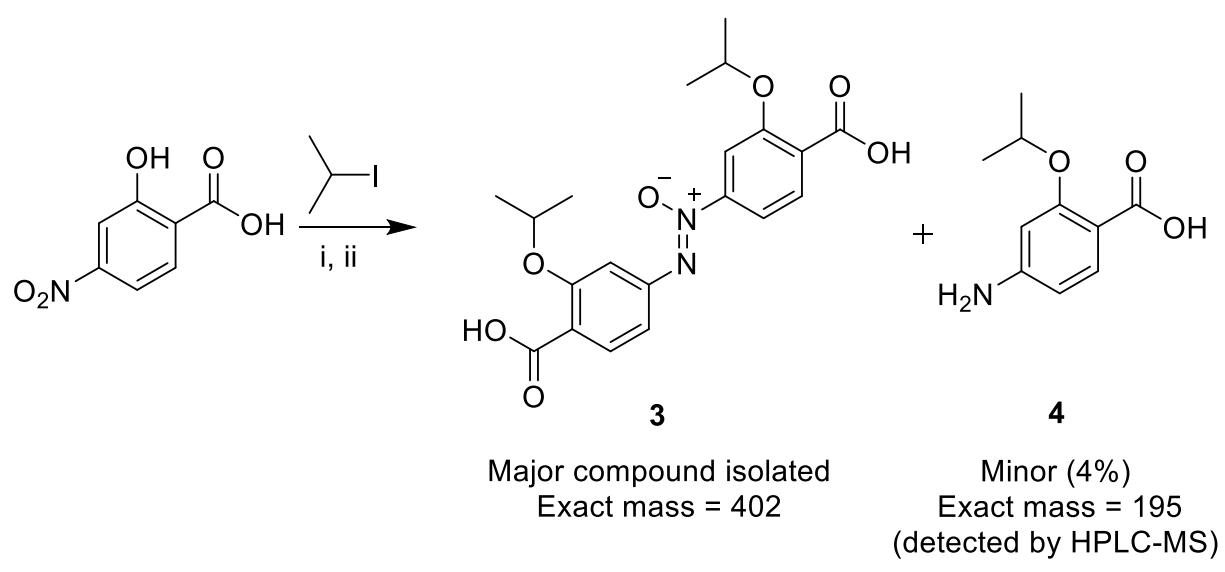

Scheme 2. Main compound isolated (3) using the Adler \& Hamilton two-step strategy to synthesize $\mathbf{1 .}^{5}$ Reagents and conditions: i) $\mathrm{K}_{2} \mathrm{CO}_{3}, \mathrm{DMF}, 80^{\circ} \mathrm{C}, 16 \mathrm{~h}$; ii) $45 \%$ aq. $\mathrm{NaOH}, \mathrm{THF}: \mathrm{EtOH}(1: 2), 80^{\circ} \mathrm{C}, 15 \mathrm{~h}$.

However, 1 was not detected with temperature $\geq 80^{\circ} \mathrm{C}$ (entries 3-4) whereas 3 and a new by-product $(\mathrm{m} / \mathrm{z}$ 195), possibly corresponding to 4-amino-2-isopropoxybenzoic acid (4), were obtained predominantly (Scheme 2). When the reaction was performed with $10 \%$ aq. $\mathrm{NaOH}$ solution (entries 5-7), acid 3 was obtained as major product (approximately 77\%) regardless of the temperature used in the reaction. Altogether, azoxybenzene 3 was obtained as major by-product ( $\geq 19 \%$ ) in all cases. Of note, the use of $45 \%$ aq. $\mathrm{KOH}$ instead of $45 \% \mathrm{NaOH}$ (entry 8 ) was less efficient in producing azoxybenzene 3.

Table 1. Conditions tested and products formed during the hydrolysis of benzoate $\mathbf{2}$ with concentrated aqueous sodium hydroxide solution

\begin{tabular}{cccccc}
\hline Entry & \multicolumn{3}{c}{ Conditions $^{a}$} & \multicolumn{3}{c}{ Detected product $^{b}(\%)$} \\
\hline 1 & Base & $\mathrm{T}\left({ }^{\circ} \mathrm{C}\right)^{c}$ & $\mathbf{1}$ & $\mathbf{3}$ & $\mathbf{4}$ \\
2 & 40 & 81 & 19 & 0 \\
3 & $45 \%$ aq. $\mathrm{NaOH}$ & 60 & 70 & 23 & 7 \\
4 & 80 & 0 & 96 & 4 \\
5 & 100 & 0 & 49 & 51 \\
6 & $10 \%$ aq. $\mathrm{NaOH}$ & 60 & 76 & 24 & 0 \\
7 & & 100 & 79 & 24 & 0 \\
8 & $45 \%$ aq. $\mathrm{KOH}$ & 80 & 39 & 21 & 0 \\
\hline
\end{tabular}

${ }^{a}$ Reactions were performed at $1 \mathrm{mmol}$ scale following the same protocol as reported ${ }^{5}$ with the conditions indicated in the Table. ${ }^{b}$ The products were detected by HPLC-MS. ${ }^{c}$ The internal temperature of the reaction mixture was controlled with a thermometer.

When the synthesis was repeated working at room temperature, compound $\mathbf{2}$ was isolated in $71 \%$ yield after silica chromatography (Scheme 3). Treatment of pure benzoate $\mathbf{2}$ with lithium hydroxide in THF/water at room temperature yielded benzoic acid 1 (83\%) after column chromatography. When both steps of the reaction were performed at room temperature, an overall yield of $82 \%$ was achieved without the necessity of isolating intermediate $\mathbf{2}$. It should be noted that in the first step of this synthesis, the dialkylated intermediate $\mathbf{2}$ was detected (HPLC-MS) as a mixture with approximately 15-33\% of the final product $\mathbf{1 .}$ 


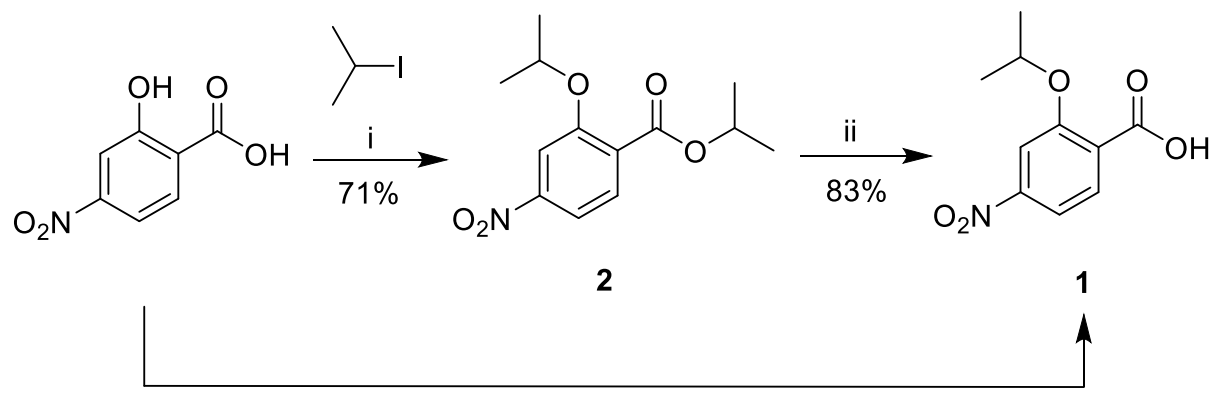

without isolating 2: $82 \%$ overall

Scheme 3. Synthesis of 3 in two steps. Reagents and conditions: i) $\mathrm{K}_{2} \mathrm{CO}_{3}, \mathrm{DMF}, \mathrm{rt}, 2 \mathrm{O}$; ii) LiOH, THF: $\mathrm{H}_{2} \mathrm{O}(1: 1)$, $\mathrm{rt}, 12 \mathrm{~h}$, then $1 \mathrm{M} \mathrm{HCl}$.

\section{Elucidation of compound 3 structure}

${ }^{1} \mathbf{H}$ nuclear magnetic resonance spectroscopy. The ${ }^{1} \mathrm{H}$ NMR data of compounds $\mathbf{1}, \mathbf{2}$, and $\mathbf{3}$ are gathered in Table 2. Compound 1 spectrum shows one septuplet for the $\mathrm{CH}(\mathrm{Me})_{2}(\mathrm{H}-12)$ whereas compound 2 shows two septuplets: one accounting for the phenolic $\mathrm{H}-12$ of the $\mathrm{O}^{i} \operatorname{Pr}$ group at $4.87 \mathrm{ppm}(\mathrm{J}=6.0 \mathrm{~Hz}, 1 \mathrm{H})$ and the other one corresponding to the benzoate $\mathrm{O}^{\prime} \mathrm{Pr}$ group that appear downfield at $5.14 \mathrm{ppm}(\mathrm{J}=6.0 \mathrm{~Hz}, 1 \mathrm{H}, \mathrm{H}-15)$. The ${ }^{1} \mathrm{H}$ NMR spectrum of $\mathbf{3}$ in DMSO- $d_{6}$ is consistent with an unsymmetrical molecule, with two septuplets corresponding to two $\mathrm{C}-\mathrm{H}$ groups from the isopropoxy substituents at 4.81 and $4.69 \mathrm{ppm}$, respectively (Table 2). The septuplet at $4.8 \mathrm{ppm}$, with similar chemical shifts in compounds $\mathbf{1}, \mathbf{2}$, and $\mathbf{3}$, was attributed to the phenolic isopropyl $\mathrm{H}-12$. In contrast, the septuplet corresponding to $\mathrm{H}-12$ ' appears upfield at 4.69 ppm (Table 2). Six aromatic $H$ are observed in compound 3 with multiplicities corresponding to two $A B X$ patterns for $H$ $1,3,4$ and $\mathrm{H}-1^{\prime}, 3^{\prime}, 4^{\prime}$, respectively. Peak assignation was done with the help of Heteronuclear Multiple-bond Correlation (HMBC) and Heteronuclear Simple Quantum Correlation (HSQC) experiments.

${ }^{13} \mathrm{C}$ and ${ }^{15} \mathrm{~N}$ NMR spectroscopy and GIAO calculations. The geometry of compound 3 has been optimized at the B3LYP/6-311++G(d,p) computational level ${ }^{7-9}$ with the Gaussian program (Gaussian-16, A03). ${ }^{10}$ Frequency calculations have been carried out to confirm that the structure obtained corresponds to an energetic minimum. The ${ }^{1} \mathrm{H},{ }^{13} \mathrm{C}$, and ${ }^{15} \mathrm{~N}$ chemical shifts of compound 3 reported in Table 3 were obtained with the

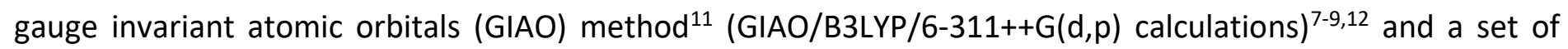
linear correlations ${ }^{13,14}$ established earlier to transform absolute shielding values $(\sigma, \mathrm{ppm})$ into chemical shifts $(\delta, \mathrm{ppm})$. The solvent has been simulated using the polarizable continuum model $(\mathrm{PCM})^{15}$ with the DMSO parameter in the geometry optimization, frequency and NMR calculations. The Cartesian coordinates of the minimum are gathered in the Supporting Information. These calculated values were in good agreement with the experimental ones (Table 3). 
Table $2 .{ }^{1} \mathrm{H}$ NMR experimental data of compounds $\mathbf{1}, \mathbf{2}$ and $\mathbf{3}$ in DMSO- $d_{6}$

\begin{tabular}{|c|c|c|c|}
\hline & $\mathrm{O}_{2} \mathrm{~N}^{-}$ & $\left.\right|_{14} ^{13}$ & (11) \\
\hline & 1 & 2 & 3 \\
\hline Atom & $\left(300 \mathrm{MHz}, \mathrm{DMSO}-d_{6}\right)$ & $\left(400 \mathrm{MHz}, \mathrm{DMSO}-d_{6}\right)$ & $\left(500 \mathrm{MHz}, \mathrm{DMSO}-d_{6}\right)$ \\
\hline $\mathrm{H}-1$ & $7.85(\mathrm{~d}, J=2.0 \mathrm{~Hz}, 1 \mathrm{H})$ & $7.87(\mathrm{~d}, J=2.0 \mathrm{~Hz}, 1 \mathrm{H})$ & $7.91(\mathrm{~d}, J=2.0 \mathrm{~Hz}, 1 \mathrm{H})$ \\
\hline$H-1^{\prime}$ & & & $7.79(\mathrm{~d}, J=1.8 \mathrm{~Hz}, 1 \mathrm{H})$ \\
\hline $\mathrm{H}-3$ & $7.81(\mathrm{dd}, J=8.4,2.0 \mathrm{~Hz}, 1 \mathrm{H})$ & $7.82(\mathrm{dd}, J=8.4,2.0 \mathrm{~Hz}, 1 \mathrm{H})$ & $7.86(\mathrm{dd}, J=8.4,2.0 \mathrm{~Hz}, 1 \mathrm{H})$ \\
\hline$H-3^{\prime}$ & & & $7.62(\mathrm{dd}, J=8.3,1.8 \mathrm{~Hz}, 1 \mathrm{H})$ \\
\hline $\mathrm{H}-4$ & $7.75(\mathrm{~d}, J=8.4 \mathrm{~Hz}, 1 \mathrm{H})$ & $7.75(\mathrm{~d}, J=8.4 \mathrm{~Hz}, 1 \mathrm{H})$ & $7.77(\mathrm{~d}, J=8.4 \mathrm{~Hz}, 1 \mathrm{H})$ \\
\hline$H-4^{\prime}$ & & & $7.74(\mathrm{~d}, J=8.3 \mathrm{~Hz}, 1 \mathrm{H})$ \\
\hline $\mathrm{H}-10, \mathrm{H}-11$ & & & $12.82(\mathrm{br}, 2 \mathrm{H})$ \\
\hline $\mathrm{H}-12$ & $4.84($ sept, $J=6.0 \mathrm{~Hz}, 1 \mathrm{H})$ & 4.87 (sept, $J=6.0 \mathrm{~Hz}, 1 \mathrm{H})$, & 4.81 (sept, $J=6.1 \mathrm{~Hz}, 1 \mathrm{H})$ \\
\hline $\mathrm{H}-12^{\prime}$ & & & $4.69($ sept, $J=6.1 \mathrm{~Hz}, 1 \mathrm{H})$ \\
\hline $\mathrm{H}-13,14$ & $1.30(\mathrm{~d}, J=6.0 \mathrm{~Hz}, 6 \mathrm{H})$. & $1.31(\mathrm{~d}, J=6.0 \mathrm{~Hz}, 6 \mathrm{H})$ & $1.32(\mathrm{~d}, J=6.1 \mathrm{~Hz}, 6 \mathrm{H})$ \\
\hline $\mathrm{H}-13^{\prime}, 14^{\prime}$ & & & $1.31(\mathrm{~d}, J=6.0 \mathrm{~Hz}, 6 \mathrm{H})$ \\
\hline $\mathrm{H}-15$ & & 5.14 (sept, $J=6.0 \mathrm{~Hz}, 1 \mathrm{H})$ & \\
\hline $\mathrm{H}-16,17$ & & $1.30(\mathrm{~d}, J=6.0 \mathrm{~Hz}, 6 \mathrm{H})$ & \\
\hline
\end{tabular}

Table 3. NMR chemical shifts (ppm) of compound 3

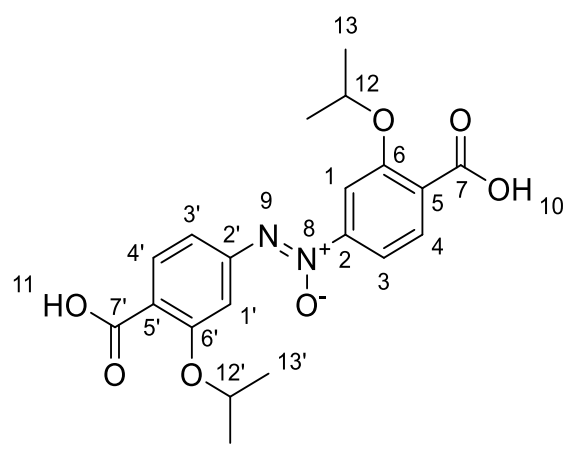

\begin{tabular}{cccccccccc}
\hline Atom & \multicolumn{2}{c}{ Experimental (DMSO- $\left.\mathrm{d}_{6}\right)$} & \multicolumn{3}{c}{ Calcd (GIAO/PCM) } & \multicolumn{3}{c}{$|\Delta|^{a}$} \\
\hline & $\delta_{\mathrm{H}}$ & $\delta_{\mathrm{C}}$ & $\delta_{\mathrm{N}}$ & $\delta_{\mathrm{H}}$ & $\delta_{\mathrm{C}}$ & $\delta_{\mathrm{N}}$ & $\delta_{\mathrm{H}}$ & $\delta_{\mathrm{C}}$ & $\delta_{\mathrm{N}}$ \\
\hline 1 & 7.91 & 108.9 & & 8.10 & 106.7 & & 0.19 & 2.2 & \\
2 & & 149.9 & & & 153.5 & & & 3.6 & \\
3 & 7.86 & 114.0 & & 8.21 & 114.1 & & 0.35 & 0.1 & \\
4 & 7.77 & 130.8 & & 8.30 & 134.9 & & 0.53 & 4.1 & \\
5 & & 127.4 & & & 120.4 & & & 7.0 & \\
6 & & 156.3 & & & 158.4 & & & 2.1 & \\
7 & & 166.9 & & & 165.3 & & & 1.6 & \\
\hline
\end{tabular}


Table 3. Continued

\begin{tabular}{cccccccccc}
\hline Atom & \multicolumn{2}{c}{ Experimental (DMSO-d $)$} & \multicolumn{3}{c}{ Calcd (GIAO/PCM) } & \multicolumn{3}{c}{$|\Delta \delta|^{a}$} \\
\hline \multicolumn{1}{c}{$\delta_{\mathrm{H}}$} & $\delta_{\mathrm{C}}$ & $\delta_{\mathrm{N}}$ & $\delta_{\mathrm{H}}$ & $\delta_{\mathrm{C}}$ & $\delta_{\mathrm{N}}$ & $\delta_{\mathrm{H}}$ & $\delta_{\mathrm{C}}$ & $\delta_{\mathrm{N}}$ \\
\hline 8 & & & -55.1 & & & -60 & & & 4.9 \\
9 & & & -49.6 & & & -54.4 & & & 4.8 \\
10 & 12.82 & & & 11.17 & & & 1.65 & & \\
11 & 12.82 & & & 11.25 & & & 1.57 & & \\
12 & 4.81 & 71.7 & & & 76.9 & & 0.06 & 5.2 & \\
13 & 1.32 & 21.7 & & 1.38 & 19.7 & & 0.06 & 0.2 & \\
$1^{\prime}$ & 7.79 & 111.4 & & 9.16 & 106.2 & & 1.37 & 5.2 & \\
$2^{\prime}$ & & 146.3 & & & 148.4 & & & 2.1 & \\
$3^{\prime}$ & 7.62 & 116.9 & & 7.41 & 124.0 & & 0.21 & 7.1 & \\
$4^{\prime}$ & 7.74 & 130.77 & & 8.34 & 134.0 & & 0.6 & 3.2 & \\
$5^{\prime}$ & & 124.0 & & & 118.5 & & & 5.5 & \\
$6^{\prime}$ & & 156.2 & & & 158.4 & & & 2.2 & \\
$7^{\prime}$ & & 167.0 & & & 165.5 & & & 1.5 & \\
$12^{\prime}$ & 4.69 & 71.3 & 5.09 & 75.9 & & 0.40 & 4.6 & \\
$13^{\prime}$ & 1.31 & 21.8 & 1.56 & 19.9 & & 0.25 & 1.5 & \\
\hline
\end{tabular}

${ }^{a}$ Absolute value of the difference between the calculated and experimental chemical shifts

When recording the ${ }^{15} \mathrm{~N}$ NMR spectrum of 3 in DMSO- $d_{6}$ by g-HMBC using the standard $J$ value of $8 \mathrm{~Hz}$, no clear signals were observed due to high signal to noise ratio. Since the intensity of cross peaks depends on the heteronuclear $\left({ }^{15} \mathrm{~N}-{ }^{1} \mathrm{H}\right)$ long-range coupling constants, we surmised that the $J$ value used in the g-HMBC experiment was not a convenient one. ${ }^{16}$ Hence, we calculated the ${ }^{3} J_{\mathrm{NH}}$ and ${ }^{4} J_{\mathrm{NH}}$ coupling constants of 3 at the B3LYP/6-311++G(d,p) level of theory. As shown in Figure 1, the calculated ${ }^{3} J_{\mathrm{NH}}$ and ${ }^{4} J_{\mathrm{NH}}$ values are in the range 0.41 to $2.38 \mathrm{~Hz}$, which explains the failure of the first experiment using $J=8 \mathrm{~Hz}$. In the repeated g-HMBC experiment optimized for $J=2.0 \mathrm{~Hz}$, two cross-peaks at -55.1 and $-49.6 \mathrm{ppm}$ were observed that are consistent with the chemical shifts of $\mathrm{N}-8\left(\mathrm{~N}^{+}-\mathrm{O}^{-}\right)$and $\mathrm{N}-9$, respectively. These chemical shifts were in good agreement with the calculated values (Table 3 ) and the reported values for trans-azoxybenzene (-54.1 and -46.7 ppm, respectively) ${ }^{17}$ and $4^{\prime}$-substituted trans-azoxybenzenes. ${ }^{18,19}$

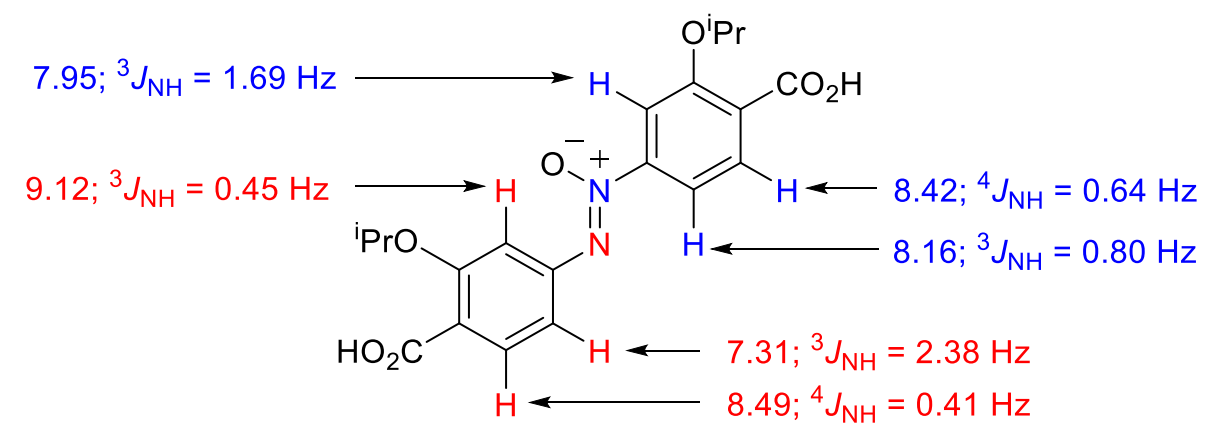

Figure 1. Calculated ${ }^{3} J_{\mathrm{NH}}$ and ${ }^{4} \mathrm{~J}_{\mathrm{NH}}$ coupling constants and chemical shifts of 3. 
Infrared spectroscopy. The IR spectrum of 3 was recorded from 4000 to $400 \mathrm{~cm}^{-1}$ on a FT-IR spectrometer fitted with a diamond single-bounce ATR. A broad band at $2971 \mathrm{~cm}^{-1}(\mathrm{COO}-\mathrm{H})$ and a strong band at $1682 \mathrm{~cm}^{-1}$ $(\mathrm{C}=\mathrm{O})$ are indicative of a dicarboxylic acid derivative. The antisymmetric stretching $\left(\mathrm{V}_{\mathrm{as}}\right)$ of $-\mathrm{N}=\mathrm{N}-\mathrm{O}$ is observed at $1485 \mathrm{~cm}^{-1}$. The $\mathrm{N}=\mathrm{N}$ stretch vibration is observed at $1408-1359 \mathrm{~cm}^{-1}$ which fits within the region of transazoxybenzenes. ${ }^{20}$ The strong bands at $1290-1237 \mathrm{~cm}^{-1}$ are assigned to the $\mathrm{CN}(\mathrm{O})$ stretch with the oxygencoordinated nitrogen. The assignment of the $\mathrm{N} \rightarrow \mathrm{O}$ bond stretch is difficult due to overlapping with other vibrations. In the literature, it has been assigned to modes in the $1330-1295 \mathrm{~cm}^{-1}$ region for transazoxybenzene. ${ }^{21}$ In our experiment, this could be related to the strong signal at $1290 \mathrm{~cm}^{-1}$. The $\mathrm{N} \rightarrow \mathrm{O}$ stretch contributes to the peak observed at $1136-1077 \mathrm{~cm}^{-1}$. The peak at $1178 \mathrm{~cm}^{-1}$ (non-resolved doublet) is indicative of the isopropyl group bonded to an oxygen. A medium band at $1112 \mathrm{~cm}^{-1}$ is assigned to phenyl CC stretch/CH in-plane bends in azoxybenzenes. A medium band at $855 \mathrm{~cm}^{-1}$ is assigned to azoxybenzenes.

\section{Discussion}

Our repeated attempts to synthesize 2-isopropoxy-4-nitrobenzoic acid 1 using the two-step protocol reported previously led to the formation of the unknown (Z)-1,2-bis(4-carboxy-3-isopropoxyphenyl)diazene-1-oxide (3) almost exclusively. Even though 1 was obtained as minor product of the synthesis in some cases, we were unable to reproduce the reported results. This was disconcerting because this major product was not even mentioned by the authors who reported an intriguing $72 \%$ yield of $\mathbf{1}$, without any chromatographic purification, for this reaction. ${ }^{5}$

The conversion of nitrobenzenes to azoxybenzenes by heating nitro derivatives with alkaline solution such as alcoholic sodium or potassium alkoxide has been known for more than one hundred years ago. ${ }^{22,23}$ The formation of azoxybenzene is thought to occur through the condensation of an aryl nitroso with an aryl hydroxylamine formed in situ upon reduction of nitroarenes (Figure 2). Recently, Wei and Shi showed that nitrobenzenes could be selectively reduced to azoxybenzenes in 74\% yield with alcohols (1-propanol> ethanol) as the hydrogen source and $\mathrm{KOH}$ as the promoter (e.g. octane/1-propanol/50 ${ }^{\circ} \mathrm{C} / 24 \mathrm{~h}$ ). With these conditions, sodium hydroxide appeared to be less effective. ${ }^{24}$ Accordingly, the harsh conditions used in the hydrolysis step by Adler \& Hamilton ( $45 \%$ aq. $\mathrm{NaOH} / \mathrm{THF}-\mathrm{EtOH} / 80^{\circ} \mathrm{C} / 15 \mathrm{~h}$ ) were highly compatible with the formation of azoxybenzene as reported in the literature. ${ }^{22-25}$ Our experiments confirmed that azoxybenzene 3 is a major byproduct of this synthesis when concentrated aqueous solution (10\% or $45 \%$ ) of sodium hydroxide in $\mathrm{THF}-\mathrm{EtOH}$ is used for the hydrolysis step. However, compound 1 was obtained in reasonable yield (approximately 75\% detected by HPLC-MS of the crude reaction mixture) when lower temperatures were used (i.e. 40 and $60{ }^{\circ} \mathrm{C}$ ). Interestingly, and in contrast to the findings of Wei and $\mathrm{Shi}^{24}$ the protocol reported here using $45 \%$ $\mathrm{NaOH} / \mathrm{THF}-\mathrm{EtOH} / 80^{\circ} \mathrm{C}$ was more efficient than $\mathrm{KOH}$ to produce the azoxybenzene derivative.

Two more synthetic protocols to prepare 1 have been reported in the literature posterior to Adler's work. 6,26,27 These three-steps syntheses consist in the protection of 2-hydroxy-4-nitrobenzoic acid as methyl ester followed by alkylation of the 2-OH group with 2-propanol under Mitsunobu conditions ${ }^{26}$ or with 2bromopropane in the presence of base (e.g. $\left.\mathrm{K}_{2} \mathrm{CO}_{3}\right) \cdot{ }^{27}$ Then, the methyl ester is hydrolysed with aqueous $\mathrm{NaOH}$ working at room temperature or $65{ }^{\circ} \mathrm{C}$ to give the desired product 1 with $63 \%$ and $82 \%$ overall yields, respectively. These synthetic protocols, which use lower temperature for the hydrolysis step with aqueous $\mathrm{NaOH}$, are consistent with our own observations. Hence, the most probable explanation for the discrepancy between our results and the reported ones is an inadequate measurement (or report) of the reaction temperature in Adler \& Hamilton's work. These results underscore the importance of accurate internal temperature control during the hydrolysis step when concentrated aqueous $\mathrm{NaOH}$ is used. 


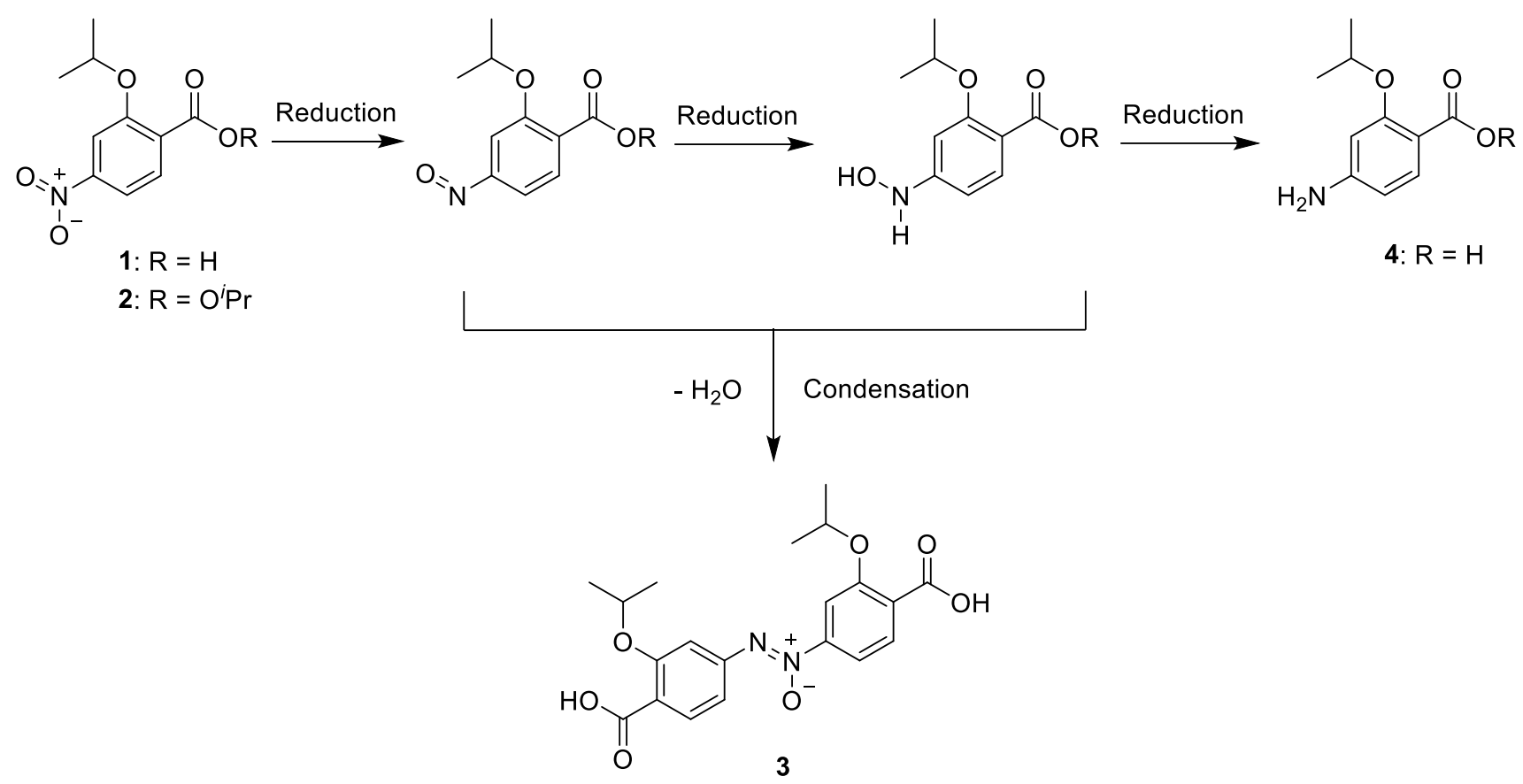

Figure 2. Putative mechanism for the formation of azoxybenzene 3.

\section{Conclusions}

To conclude, we have identified and fully characterized azoxybenzene 3 as main product (92\%) of the synthesis of 2-isopropoxy-4-benzoic acid (1) using the harsh hydrolysis conditions (45\% aq. NaOH/ THF-EtOH/ $80{ }^{\circ} \mathrm{C} / 15 \mathrm{~h}$ ) reported earlier. ${ }^{5}$ This synthetic protocol may be useful for the gram scale synthesis of 2-alkoxy trans-azoxybenzene derivatives. The use of GIAO/density-functional calculations to predict chemical shifts and coupling constants was useful in the elucidation of the NMR spectra of $\mathbf{3}$, as was shown previously. ${ }^{16}$ Alternatively, the synthesis of $\mathbf{1}$ was achieved successfully in high yield (82\% overall) working at room temperature with a two-step procedure using lithium hydroxide as base instead of concentrated $\mathrm{NaOH} / \mathrm{EtOH}-$ THF.

\section{Experimental Section}

General. ${ }^{1} \mathrm{H}$ NMR and ${ }^{13} \mathrm{C}$ NMR were recorded on a Varian Inova-300 $\left({ }^{1} \mathrm{H}: 300 \mathrm{MHz},{ }^{13} \mathrm{C}: 75.5 \mathrm{MHz}\right)$, Varian System-500 ( $\left.{ }^{1} \mathrm{H}: 500 \mathrm{MHz},{ }^{13} \mathrm{C}: 125.8 \mathrm{MHz}\right)$, and Bruker Avance III HD-400 $\left({ }^{1} \mathrm{H}: 400.13 \mathrm{MHz},{ }^{13} \mathrm{C}: 100.62 \mathrm{MHz}\right.$, ${ }^{15} \mathrm{~N}$ : $40.54 \mathrm{MHz}$ ) spectrometers using solvent peak as internal reference (DMSO- $\mathrm{d}_{6}: 2.49 \mathrm{ppm}$ for ${ }^{1} \mathrm{H}$ and 39.5 ppm for $\left.{ }^{13} \mathrm{C}\right)$. For ${ }^{15} \mathrm{~N} N \mathrm{NMR}$, nitromethane $(0.00 \mathrm{ppm})$ was used as external standard. Inverse proton detected heteronuclear shift correlation spectra, $\left({ }^{1} \mathrm{H}-{ }^{13} \mathrm{C}\right)$ gs-HMQC, $\left({ }^{1} \mathrm{H}_{-}{ }^{13} \mathrm{C}\right)$ gs-HMBC, and $\left({ }^{1} \mathrm{H}-{ }^{15} \mathrm{~N}\right)$ gs-HMQC, were carried out with the standard pulse sequences to assign the ${ }^{1} \mathrm{H},{ }^{13} \mathrm{C}$, and ${ }^{15} \mathrm{~N}$ signals. The chemical shifts $(\delta)$ and coupling constants $(\mathrm{J})$ are expressed in ppm and hertz respectively. Carbon attribution $\mathrm{C}, \mathrm{CH} \mathrm{CH}_{2}$ and $\mathrm{CH}_{3}$ were determined by ${ }^{13} \mathrm{C}, \mathrm{HMBC}$ and $\mathrm{HMQC}$ experiments. InfraRed (IR) spectra were recorded on a PerkinElmer Spectrum Two FT-IR spectrometer fitted with a diamond single-bounce ATR. The spectrum was collected at 4 $\mathrm{cm}^{-1}$ spectral resolution. The compound was pressed on the diamond crystal and measured directly without 
any further sample preparation. Melting points were determined by using a Mettler Toledo MP70 apparatus. Merck silica gel (0.043-0.063 mm) was used for flash chromatography. Anhydrous solvents and starting materials were directly used as obtained commercially. Aqueous solutions of sodium hydroxide (Panreac ${ }^{\circledR}$ $\mathrm{NaOH}$ pellets, pure, pharma grade, 98.8\% CoA purity) and potassium hydroxide (Panreac ${ }^{\circledR} \mathrm{KOH} 85 \%,(86.2 \%$ CoA purity) pellets, USP-NF, Bp, Ph. Eur.) were prepared with distilled water. The solutions were allowed to cool to room temperature and filtered through filter paper before use.

Procedures. Synthesis of $\mathbf{3}$ following the two-step protocol reported earlier ${ }^{5}$ for the preparation of $\mathbf{1}$ (similar results were obtained in different attempts working at 1 and $27 \mathrm{mmol}$ scale).

To a round-bottom screw cap pressure flask was added sequentially 2-hydroxy-4-nitrobenzoic acid (1099 mg, 6 $\mathrm{mmol}$ ), anhydrous $\mathrm{N}, \mathrm{N}$-dimethylformamide $(12.5 \mathrm{~mL}), \mathrm{K}_{2} \mathrm{CO}_{3}(2070 \mathrm{mg}, 15 \mathrm{mmol}$ ), and 2-iodopropane (1.5 $\mathrm{mL}$, $15 \mathrm{mmol})$. The flask was capped and the reaction was stirred at $80{ }^{\circ} \mathrm{C}$ for $20 \mathrm{~h}$. After being allowed to cool to room temperature, the mixture was diluted with ethyl acetate and washed successively with water $(2 \times)$ and brine. The organic layer was dried over magnesium sulfate, filtered, and then the solution was evaporated to dryness to obtain a brownish oil. This material was taken up in tetrahydrofuran $(5 \mathrm{~mL})$, to which was added ethanol $(12 \mathrm{~mL})$ and $45 \%$ aqueous $\mathrm{NaOH}$ solution $(12 \mathrm{~mL})$. This mixture was allowed to stir at $80{ }^{\circ} \mathrm{C}$ (i.e. internal temperature) for $15 \mathrm{~h}$. The resulting solution was allowed to cool to ambient temperature and then diluted with distilled water and washed twice with ethyl acetate. The aqueous solution was then acidified using $1 \mathrm{M}$ aqueous $\mathrm{HCl}$ and extracted twice with diethyl ether. The combined organic layers were washed with an aqueous saturated sodium chloride solution, dried over magnesium sulfate, filtered, and solvent was removed under vacuum. Recrystallization from ethyl acetate yielded (Z)-1,2-bis(4-carboxy-3isopropoxyphenyl)diazene-1-oxide (3) as yellowish solid (1237 mg, 92\%). mp $225.7{ }^{\circ} \mathrm{C}$. IR (solid, $v_{\max }, \mathrm{cm}^{-1}$ ): 2971, 2925, 2869, 2641, 2563, 1682, 1580, 1551, 1485, 1446, 1408, 1387, 1290, 1237, 1178, 1137, $1112,920$. ${ }^{1} \mathrm{H}$ NMR data appear in Tables 2 and $3 .{ }^{13} \mathrm{C}\left\{{ }^{1} \mathrm{H}\right\}$ NMR (DMSO-d6, $101 \mathrm{MHz}$ ) $\delta_{\mathrm{c}} 167.0$ (C-7'), 166.9 (C-7), 156.3 (C6), 156.2 (C-6'), 149.9 (C-2), 146.3 (C-2'), 130.82 (C-4), 130.77 (C-4'), 127.4 (C-5), 124.0 (C-5'), 116.9 (C-3'), 114.0 (C-3), 111.4 (C-1'), 108.9 (C-1), 71.7 (C-12), 71.3 (C-12'), 21.8 (C-13'), 21.7 (C-13). Anal. calcd. for $\mathrm{C}_{20} \mathrm{H}_{22} \mathrm{~N}_{2} \mathrm{O}_{7}$ (403.14): C, 59.70; $\mathrm{H}, 5.51 ; \mathrm{N}, 6.96$. Found: $\mathrm{C}, 59.83 ; \mathrm{H}, 5.79 ; \mathrm{N}, 6.76$.

Synthesis of 2-isopropoxy-4-nitrobenzoic acid (1) using LiOH. Step 1. To a round-bottom flask containing a magnetic stir bar was added sequentially 2-hydroxy-4-nitrobenzoic acid (2.8 g, $15.2 \mathrm{mmol})$, anhydrous $N, N$ dimethylformamide $(20 \mathrm{~mL}), \mathrm{K}_{2} \mathrm{CO}_{3}(5.24 \mathrm{~g}, 38 \mathrm{mmol})$, and 2-iodopropane $(3.8 \mathrm{~mL}, 38 \mathrm{mmol})$. The reaction was stirred at room temperature for $16 \mathrm{~h}$. The mixture was diluted with dichloromethane and washed with distilled water twice followed by an aqueous saturated sodium chloride solution (brine). The organic layer was dried over magnesium sulfate, filtered, and the solvent was evaporated under vacuum. Column chromatography was performed using hexane/ethyl acetate: 100/0 $\rightarrow 97 / 3$ as elution system, yielding isopropyl 2-isopropoxy-4-nitrobenzoate (2) as yellowish oil (2.9 g, 71.4\%). ${ }^{1} \mathrm{H}$ NMR: see Table $2 .{ }^{13} \mathrm{C}\left\{{ }^{1} \mathrm{H}\right\} \mathrm{NMR}$ (DMSO-d, $101 \mathrm{MHz}$ ) $\delta_{\mathrm{C}} 164.8$ (C-7), 156.0 (C-6), 149.9 (C-2), 130.7 (C-4), 128.8 (C-5), 115.0 (C-3), 108.8 (C-1), 71.8 (C-12), 68.9 (C-15), 21.52 (C-13, C-14), 21.49 (C-16, C-17). MS (ESI $\left.{ }^{+}\right) \mathrm{m} / z 268.37$ (M+H). Anal. calcd for $\mathrm{C}_{13} \mathrm{H}_{17} \mathrm{NO}_{5}$ : $\mathrm{C}, 58.42 ; \mathrm{H}, 6.41 ; \mathrm{N}, 5.24$. Found: $\mathrm{C}, 58.00 ; \mathrm{H}, 6.33 ; \mathrm{N}, 5.36$.

Step 2. A Kimax tube was loaded with 2 (300.5 mg, $1.1 \mathrm{mmol})$, $\mathrm{LiOH}(135.3 \mathrm{mg}, 5.7 \mathrm{mmol}$ ) and $16 \mathrm{~mL} \mathrm{THF/H}$ (1:1). The reaction mixture was stirred at room temperature for $12 \mathrm{~h}$. THF was then evaporated under vacuum and the aqueous solution acidified with $1 \mathrm{M}$ aqueous $\mathrm{HCl}$. The product was extracted with dichloromethane, washed with brine, and dried over magnesium sulfate. Finally, the solvent was removed under vacuum. Recrystallization from ethyl acetate yielded 1 as a light yellow solid (212 mg, 83.4\%). mp $142-143{ }^{\circ} \mathrm{C}$ (lit. ${ }^{6} 146$ $147{ }^{\circ} \mathrm{C}$ ). HPLC-UV: $100 \% .{ }^{1} \mathrm{H}$ NMR: see Table $2 .{ }^{13} \mathrm{C}\left\{{ }^{1} \mathrm{H}\right\}$ NMR (DMSO- $\left.d_{6}, 126 \mathrm{MHz}\right) \delta 166.7$ (C-7), 156.0 (C-6), 
149.7 (C-2), 130.8 (C-4), 129.8 (C-5), 115.1 (C-3), 109.4 (C-1), 71.9 (C-12), 21.6 (C-13, C-14). MS (ESI $\left.{ }^{+}\right) \mathrm{m} / z 226.1$ $(\mathrm{M}+\mathrm{H})$. Anal. calcd for $\mathrm{C}_{10} \mathrm{H}_{11} \mathrm{NO}_{5} \cdot 0.5 \mathrm{H}_{2} \mathrm{O}: \mathrm{C}, 51.28 ; \mathrm{H}, 5.16 ; \mathrm{N}, 5.98$. Found: 50.89; $\mathrm{H}, 4.95 ; \mathrm{N}, 5.95$.

Alternative protocol for the synthesis of $\mathbf{1}$ (without isolating the benzoate intermediate): to a stirred solution of 2-hydroxy-4-nitrobenzoic acid (500 mg, $2.7 \mathrm{mmol}$ ) in dry DMF (5 mL) was added $\mathrm{K}_{2} \mathrm{CO}_{3}(943 \mathrm{mg}, 6.8 \mathrm{mmol})$ at once. After 5 minutes stirring, 2-iodopropane $(0.7 \mathrm{~mL}, 6.8 \mathrm{mmol})$ was added dropwise to the mixture. After 16 hours stirring at room temperature, the crude reaction mixture was diluted with EtOAc and extracted with $1 \mathrm{M}$ aq. $\mathrm{HCl}$. The organic phase was washed with saturated $\mathrm{NaCl}$ solution, dried over $\mathrm{Na}_{2} \mathrm{SO}_{4}$, filtered and the solvent was evaporated under vacuum to yield a yellowish oil (HPLC > 95\%). The crude oil was diluted in a mixture of THF/ $\mathrm{H}_{2} \mathrm{O}(1: 1,10 \mathrm{~mL})$, followed by the addition of $\mathrm{LiOH}(240 \mathrm{mg}, 10 \mathrm{mmol})$. After 6 hours stirring at room temperature, the crude reaction mixture was diluted with $\mathrm{CH}_{2} \mathrm{Cl}_{2}$ and extracted with $1 \mathrm{M}$ aq. $\mathrm{HCl}$. The organic phase was washed with brine, dried over $\mathrm{Na}_{2} \mathrm{SO}_{4}$ and evaporated under vacuum. Compound 1 was obtained as yellowish solid ( $369 \mathrm{mg}, 82 \%$ ) by recrystallization from EtOAc.

\section{Acknowledgements}

This work was supported by the Spanish Ministerio de Ciencia, Innovación y Universidades (MCIU/AEI/FEDER, UE; grant RTI2018-093940-B-I00). J. J. Nué-Martínez fellowship is funded by the Programa Nacional de Becas y Crédito Educativo of the Peruvian Government. The technical assistance of Dr. F. Reviriego (IR spectroscopy) is gratefully acknowledged.

\section{Supplementary Material}

NMR spectra of compounds 1-3. Electronic energy (hartree), number of imaginary frequencies and cartesian coordinates $(\AA ̊)$ of compound 3 calculated at B3LYP/6-311++G(d,p)/PCM(DMSO) computational level.

\section{References}

1. Dardonville, C.; Nué Martínez, J. J. Curr. Med. Chem. 2017, 24, 1.

http://dx.doi.org/10.2174/0929867324666170623091522

2. Ríos Martínez, C. H.; Nué Martínez, J. J.; Ebiloma, G. U.; de Koning, H. P.; Alkorta, I.; Dardonville, C. Eur. J. Med. Chem. 2015, 101, 806.

http://dx.doi.org/10.1016/i.ejmech.2015.07.013

3. Ríos Martínez, C.; Miller, F.; Ganeshamoorthy, K.; Glacial, F.; Kaiser, M.; de Koning, H.; Eze, A.; Lagartera, L.; Herraiz, T.; Dardonville, C. Antimicrob. Agents Chemother. 2015, 59, 890.

http://dx.doi.org/10.1128/AAC.03958-14

4. Montalvo-Quirós, S.; Taladriz-Sender, A.; Kaiser, M.; Dardonville, C. J. Med. Chem. 2015, 58, 1940. http://dx.doi.org/10.1021/jm5018303

5. Adler, M. J.; Hamilton, A. D. J. Org. Chem. 2011, 76, 7040.

http://dx.doi.org/10.1021/i0200917d 
6. Azzarito, V.; Prabhakaran, P.; Bartlett, A. I.; Murphy, N. S.; Hardie, M. J.; Kilner, C. A.; Edwards, T. A.; Warriner, S. L.; Wilson, A. J. Org. Biomol. Chem. 2012, 10, 6469.

http://dx.doi.org/10.1039/C2OB26262B

7. Becke, A. D. J. Chem. Phys. 1993, 98, 5648.

http://dx.doi.org/10.1063/1.464913

8. Lee, C.; Yang, W.; Parr, R. G. Phys. Rev. B 1988, 37, 785.

http://dx.doi.org/ 10.1103/PhysRevB.37.785

9. Frisch, M. J.; Pople, J. A.; Binkley, J. S. J. Chem. Phys. 1984, 80, 3265.

http://dx.doi.org/10.1063/1.447079

10. Frisch, M. J.; Trucks, G. W.; Schlegel, H. B.; Scuseria, G. E.; Robb, M. A.; Cheeseman, J. R.; Scalmani, G.; Barone, V.; Petersson, G. A.; Nakatsuji, H.; Li, X.; Caricato, M.; Marenich, A. V.; Bloino, J.; Janesko, B. G.; Gomperts, R.; Mennucci, B.; Hratchian, H. P.; Ortiz, J. V.; Izmaylov, A. F.; Sonnenberg, J. L.; Williams; Ding, F.; Lipparini, F.; Egidi, F.; Goings, J.; Peng, B.; Petrone, A.; Henderson, T.; Ranasinghe, D.; Zakrzewski, V. G.; Gao, J.; Rega, N.; Zheng, G.; Liang, W.; Hada, M.; Ehara, M.; Toyota, K.; Fukuda, R.; Hasegawa, J.; Ishida, M.; Nakajima, T.; Honda, Y.; Kitao, O.; Nakai, H.; Vreven, T.; Throssell, K.; Montgomery Jr., J. A.; Peralta, J. E.; Ogliaro, F.; Bearpark, M. J.; Heyd, J. J.; Brothers, E. N.; Kudin, K. N.; Staroverov, V. N.; Keith, T. A.; Kobayashi, R.; Normand, J.; Raghavachari, K.; Rendell, A. P.; Burant, J. C.; Iyengar, S. S.; Tomasi, J.; Cossi, M.; Millam, J. M.; Klene, M.; Adamo, C.; Cammi, R.; Ochterski, J. W.; Martin, R. L.; Morokuma, K.; Farkas, O.; Foresman, J. B.; Fox, D. J. Wallingford, CT, 2016.

11. Ruud, K.; Helgaker, T.; Bak, K. L.; Jo/rgensen, P.; Jensen, H. J. r. A. J. Chem. Phys. 1993, $99,3847$. http://dx.doi.org/10.1063/1.466131

12. Ditchfield, R.; Hehre, W. J.; Pople, J. A. J. Chem. Phys. 1971, 54, 724.

http://dx.doi.org/10.1063/1.1674902

13. Silva, A. M. S.; Sousa, R. M. S.; Jimeno, M. L.; Blanco, F.; Alkorta, I.; Elguero, J. Magn. Reson. Chem. 2008, $46,859$.

http://dx.doi.org/10.1002/mrc.2272

14. Blanco, F.; Alkorta, I.; Elguero, J. Magn. Reson. Chem. 2007, 45, 797. http://dx.doi.org/10.1002/mrc.2053

15. Tomasi, J.; Mennucci, B.; Cammi, R. Chem. Rev. 2005, 105, 2999.

https://doi.org/10.1021/cr9904009

16. Alkorta, I.; Dardonville, C.; Elguero, J. Angew. Chem. Int. Ed. 2015, 54, 3997. http://dx.doi.org/10.1002/anie.201412144

17. Schwotzer, W.; Leuenberger, C.; Hoesch, L.; Dreiding, A. S.; von Philipsborn, W. Org. Magn. Reson. 1977, 9, 382.

https://doi.org/10.1002/mrc.1270090620

18. Masami, S.; Yoshio, T.; Takanori, T.; Terukiyo, H.; Masao, O.; Yuho, T. Bull. Chem. Soc. Jpn 1990, 63, 702. https://doi.org/10.1246/bcsj.63.702

19. Mason, J. In PATAI'S Chemistry of Functional Groups; Rappoport, Z., Ed.; John Wiley \& Sons, Ltd.: 2009. https://doi.org/10.1002/9780470682531.pat0148

20. Tecklenburg, M. M. J.; Kosnak, D. J.; Bhatnagar, A.; Mohanty, D. K. J. Raman Spectrosc. 1997, $28,755$. https://doi.org/10.1002/(SICI)1097-4555(199710)28:10\%3C755::AID-JRS143\%3E3.0.CO;2-V

21. Gruger, A.; Le Calvé, N. Spectrochim. Acta Part A 1972, 28, 1253.

https://doi.org/10.1016/0584-8539(72)80095-3

22. Vančik, H. In Aromatic C-nitroso Compounds; Springer: Dordrecht, 2013.

23. Suter, C. M.; Dains, F. B. J. Am. Chem. Soc. 1928, 50, 2733.

https://doi.org/10.1021/ja01397a024

24. Wei, R. P.; Shi, F. Synth. Commun. 2019, 49, 688.

https://doi.org/10.1080/00397911.2019.1566472 
25. Reid, E. B.; Pritchett, E. G. J. Org. Chem. 1953, 18, 715. https://doi.org/10.1021/jo01134a017

26. Durcik, M.; Lovison, D.; Skok, Ž.; Durante Cruz, C.; Tammela, P.; Tomašič, T.; Benedetto Tiz, D.; Draskovits, G.; Nyerges, Á.; Pál, C.; Ilaš, J.; Peterlin Mašič, L.; Kikelj, D.; Zidar, N. Eur. J. Med. Chem. 2018, 154, 117. https://doi.org/10.1016/j.ejmech.2018.05.011

27. Prabhakaran, P.; Azzarito, V.; Jacobs, T.; Hardie, M. J.; Kilner, C. A.; Edwards, T. A.; Warriner, S. L.; Wilson, A. J. Tetrahedron 2012, 68, 4485. https://doi.org/10.1039/c6ob00078a

This paper is an open access article distributed under the terms of the Creative Commons Attribution (CC BY) license (http://creativecommons.org/licenses/by/4.0/) 